\title{
Energy and Exergy Analysis of Solar Triple Effect Refrigeration Cycle
}

\author{
Manoj Dixit, S. C. Kaushik, and Akhilesh Arora
}

\begin{abstract}
In this paper solar driven triple effect refrigeration cycle is investigated from the viewpoint of both energy and exergy concepts of thermodynamics. In this cycle ejector organic Rankine cycle, absorption refrigeration cycle and transcritical $\mathrm{CO}_{2}$ refrigeration cycles are integrated in order to obtain a range of temperature for varied simultaneous use. Parabolic trough collectors are used to utilize solar thermal energy for driving the refrigeration cycles. Exergy analysis determines the destruction and losses of exergy in various components and hence in overall system. Exergy efficiencies provide measure of approach to ideality while exergy destruction and losses provide measure of the deviation from ideality. Energy efficiency is found to be around $16.42 \%$ while exergy efficiency is $1.64 \%$. The maximum thermodynamic irreversibility occurs in parabolic trough collector, followed by generator of absorption refrigeration system, heat recover vapour generator and ejector.
\end{abstract}

Index Terms - Absorption refrigeration, exergy, solar energy, triple effect.

\section{INTRODUCTION}

Energy plays a significant role in the development of the world. Refrigeration and air conditioning systems alone accounts for around $30 \%$ of the global energy consumption [1]. Also, $45 \%$ of the total residential energy consumption is due to air conditioning systems [2]. There are many commercial and industrial applications where cooling is required at different temperatures simultaneously. For example, supermarkets where air conditioning can be provided by absorption refrigeration system, cooling temperatures of 0 to $-10^{\circ} \mathrm{C}$ can be provided by ejector refrigeration system and lower temperatures of around -10 to $-30^{\circ} \mathrm{C}$ can be provided by vapour compression refrigeration system. The integration of these three cooling technologies can provide the different temperatures at different magnitudes simultaneously.

In this paper absorption refrigeration, organic Rankine, ejector refrigeration and transcritical vapour compression refrigeration cycles are combined. The solar heat is used to operate ORC and ARC directly while ERC and VCR cycle are operated by turbine exhaust ant turbine power respectively. For the utilization of solar energy parabolic trough collectors (PTC) are used. For thermodynamic performance both energy and exergy analysis is carried out. Exergy analysis provides

Manuscript received October 12, 2015; revised March 8, 2016.

Manoj Dixit and S. C. Kaushik are with the Centre for Energy Studies, Indian Institute of Technology Delhi, New Delhi, 110016, India (e-mail: mandix@ces.iitd.ac.in,kaushik@ces.iitd.ac.in).

A. Arora is with the Mechanical Engineering Department, Delhi Technological University, Delhi, 110042, India (e-mail: aroraakhilesh@yahoo.com). more meaningful information as compared to energy analysis It helps in identifying site, quantity and source of thermodynamic inefficiency. Exergy destruction in each component is evaluated in order to find out the direction for potential improvement. Parametric analysis is done to examine the influence of various operating parameters on the system [3]-[14].

\section{SYSTEM DESCRIPTION}

The solar driven triple effect cycle consists of parabolic trough collector, absorption refrigeration cycle, organic Rankine cycle, ejector refrigeration cycle and transcritical vapour compression refrigeration cycle as shown in Fig. 1.

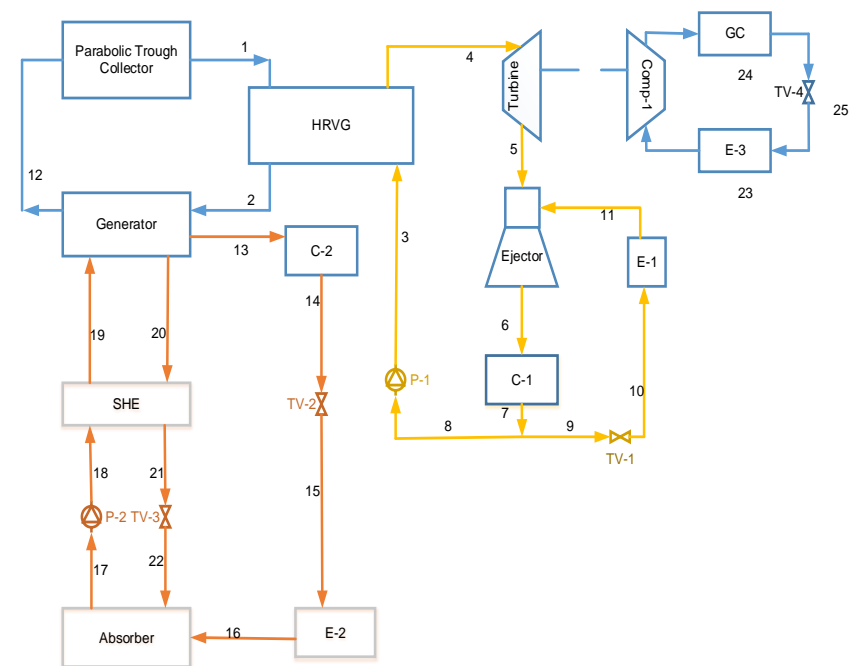

Fig. 1. PTC integrated triple effect refrigeration cycle.

The PTC are suitably employed to harness the maximum available solar energy. The parabolic trough collectors perform better with efficient tracking system. It allows focusing the entire available energy on the metallic tube (receiver) Therminol VP-1 oil is used as the working fluid in the present case. The oil transfers its heat to HRVG (1-2) and generator (2-12). The working substance used in ejector organic Rankine cycle (EORC) is R-141b. The superheated vapour of R-141b (4) is generated in HRVG and expanded in turbine. The turbine exhaust (5) act as a primary motive fluid for ERC (5-6-7-9-10-11). At the exit of the nozzle section of the ejector, the high velocity primary refrigerant vapours create vacuum at the inlet of the mixing chamber and thereby extracting secondary refrigerant vapour (11) from evaporator-1 and causes cooling effect.

The mixture of primary and secondary fluid (6) is condensed in condenser-1. The work output of turbine is fed to compressor of transcritical VCR cycle (23-24-25-26). The 
refrigerant used in the cycle is nitrous oxide $\left(\mathrm{N}_{2} \mathrm{O}\right)$. The single effect $\mathrm{LiBr}-\mathrm{H}_{2} \mathrm{O}$ absorption refrigeration cycle (13-14-15-16-17-18-19-20-21-22) consists of generator, condenser-2, evaporator-2, absorber, solution heat exchanger (SHE), pump-2 (P-2) and throttle valves (TV-2 and TV-3). The description of ARC cycle is given elsewhere [15].

\section{THERMODYNAMIC ANALYSIS}

Principle of mass conservation together with first and second law of thermodynamics is applied in order to carry out the thermodynamic analysis of PTC integrated triple effect cooling system. The general equations are:

$$
\begin{gathered}
\sum \dot{m}_{i}-\sum \dot{m}_{o}=0 \\
\sum \dot{m}_{i} x_{i}-\sum \dot{m}_{o} x_{o}=0 \\
\sum \dot{Q}-\sum \dot{W}=\sum \dot{m}_{o} h_{o}-\sum \dot{m}_{i} h_{i}
\end{gathered}
$$

The second law of thermodynamics facilitates in assessing the performance of the system based on exergy, which always decreases owing to irreversibility.

For a control volume, the exergy flow rate of a fluid, considering only physical exergy, is expressed as:

$$
\dot{E}=\dot{m}\left[\left(h-h_{0}\right)-T_{0}\left(s-s_{0}\right)\right]
$$

Exergy destruction rate for each component is calculated using equation (4)

$$
\begin{aligned}
& \dot{E} D=\sum \dot{m}_{i} \psi_{i}-\sum \dot{m}_{o} \psi_{o}+ \\
& {\left[\sum\left(\dot{Q}\left(1-T_{0} / T\right)\right)_{i}-\left(\dot{Q}\left(1-T_{0} / T\right)\right)_{o}\right]+\sum \dot{W}}
\end{aligned}
$$

\section{TABLE I: PARAMETERS USED IN THE MODELLING}

\section{Parameters}

Environment temperature $\left({ }^{\circ} \mathrm{C}\right)$

Environment pressure $(\mathrm{kPa})$

PTC oil temperature $\left({ }^{\circ} \mathrm{C}\right)$

Turbine inlet pressure $(\mathrm{kPa})$

Turbine back pressure $(\mathrm{kPa})$

Turbine isentropic efficiency $(\%)$

ERC evaporator temperature $\left({ }^{\circ} \mathrm{C}\right)$

ARC evaporator temperature $\left({ }^{\circ} \mathrm{C}\right)$

VCR evaporator temperature $\left({ }^{\circ} \mathrm{C}\right)$

Value
15
101.35
$160-180$
$900-1700$
$220-300$
85
-5
5
-35

\begin{tabular}{|ll|}
\hline Condenser-2 temperature $\left({ }^{\circ} \mathrm{C}\right)$ & 35 \\
Gas cooler temperature $\left({ }^{\circ} \mathrm{C}\right)$ & 40 \\
Gas cooler pressure $(\mathrm{MPa})$ & $8-11$ \\
Absorber temperature $\left({ }^{\circ} \mathrm{C}\right)$ & 35 \\
Pump isentropic efficiency $(\%)$ & 70 \\
HRVG efficiency $(\%)$ & 100 \\
Pinch point temperature difference $\left({ }^{\circ} \mathrm{C}\right)$ & 10 \\
Nozzle efficiency $(\%)$ & 90 \\
Mixing chamber efficiency $(\%)$ & 85 \\
Diffuser efficiency $(\%)$ & 85 \\
Length of PTC module $(\mathrm{m})$ & 12.27 \\
Width of PTC module $(\mathrm{m})$ & 5.76 \\
Total area of PTC field $\left(\mathrm{m}^{2}\right)$ & 5540 \\
Focal length $(\mathrm{m})$ & 1.71 \\
Incidence angle $\left(\mathrm{N}-\mathrm{S}\right.$ axis orientation, $\left.{ }^{\circ}\right)$ & 9.48 \\
Receiver tube outer diameter $(\mathrm{m})$ & 0.07 \\
Receiver tube inner diameter $(\mathrm{m})$ & 0.065 \\
Glass envelope outer diameter $(\mathrm{m})$ & 0.115 \\
Glass envelope inner diameter $(\mathrm{m})$ & 0.109 \\
Solar beam radiation $\left(\mathrm{W} / \mathrm{m}^{2}\right)$ & 850 \\
Intercept factor $(\mathrm{IF})$ & 0.92 \\
Mirror reflectivity $\left(\gamma_{r}\right)$ & 0.92 \\
Glass transmissivity $\left(\tau_{g}\right)$ & 0.945 \\
Solar absorptivity $\left(\alpha_{a}\right)$ & 0.94 \\
Losses due to shading $\left(\eta_{d}\right)$ & 0.98 \\
Heat removal factor $\left(F_{r}\right)$ & 0.90 \\
Temperature of sun $(K)$ & 5600 \\
\hline
\end{tabular}

The input solar power to the system is the solar power collected by the collectors or mirrors of the PTC and is given as [16]:

$$
\dot{Q}_{I}=I_{b} A_{s c} \cos \theta
$$

where $I_{b}$ is direct normal radiation (DNI) and $\theta$ is the angle of incidence.

The total exergetic solar power input to PTC is given as [17]:

$$
\dot{E}_{I}=\dot{Q}_{I}\left[1-4 / 3\left(T_{a} / T_{s}\right)+1 / 3\left(T_{a} / T_{s}\right)^{4}\right]
$$

where $T_{s}$ is the apparent black body temperature of the sun and $T_{a}$ is the ambient temperature.

The solar power absorbed by receiver/absorber of PTC can be estimated by the following equation [16].

$$
\dot{Q}_{r}=I_{b} \cdot A_{s c} \cdot K(\theta) \cdot \gamma_{r} \tau_{g} \cdot \alpha_{a} \cdot \text { IF } \eta_{d} \cdot \text { End Loss }
$$

TABLE II: ENERGY AND EXERGY RELATIONS FOR THE VARIOUS COMPONENTS OF TRIPLE EFFECT REFRIGERATION CYCLE

\begin{tabular}{|l|l|l|}
\hline Component & Energy relations & Exergy relations \\
\hline HRVG & $\dot{m}_{1}\left(h_{1}-h_{2}\right)=\dot{m}_{3}\left(h_{4}-h_{3}\right)$ & $\dot{E} D_{H R V G}=T_{0}\left(\dot{m}_{2} s_{2}-\dot{m}_{1} s_{1}+\dot{m}_{4} s_{4}-\dot{m}_{3} s_{3}\right)$ \\
\hline Turbine & $\dot{W}_{T}=\dot{m}_{4}\left(h_{4}-h_{5}\right)$ & $\dot{E} D_{T}=T_{0}\left(s_{5}-s_{4}\right)$ \\
\hline Ejector & $\dot{m}_{5} h_{5}+\dot{m}_{11} h_{11}=\left(\dot{m}_{5}+\dot{m}_{11}\right) h_{6}$ & $\dot{E} D_{e j}=T_{0}\left(\dot{m}_{6} s_{6}-\dot{m}_{5} s_{5}-\dot{m}_{11} s_{11}\right)$ \\
& $\mu=\left[\begin{array}{l}\eta_{n} \eta_{m} \eta_{d}\left(h_{p f, n 1}-h_{p f, n 2, s}\right) \\
/\left(h_{m f, d, s}-h_{m f, m}\right)\end{array}\right]^{0.5}-1$ & \\
& \multicolumn{1}{|l|}{} & \\
\hline
\end{tabular}




\begin{tabular}{|c|c|c|}
\hline Condenser-1 & $\dot{Q}_{c 1}=\dot{m}_{6}\left(h_{6}-h_{7}\right)$ & $\dot{E} D_{c 1}=\dot{m}_{6}\left(h_{6}-T_{0} s_{6}\right)-\dot{m}_{7}\left(h_{7}-T_{0} s_{7}\right)$ \\
\hline Evaporator-1 & $\dot{Q}_{e 1}=\dot{m}_{11}\left(h_{11}-h_{10}\right)$ & $\dot{E} D_{e 1}=T_{0}\left(\dot{m}_{11} s_{11}-\dot{m}_{10} s_{10}-\dot{Q}_{e 1} / T_{e 1}\right)$ \\
\hline Generator & $\dot{Q}_{g}=\dot{m}_{f}\left(h_{2}-h_{12}\right)=\dot{m}_{13} h_{13}+\dot{m}_{20} h_{20}-\dot{m}_{19} h_{19}$ & $\dot{E} D_{g}=T_{0}\left(\dot{m}_{20} s_{20}+\dot{m}_{13} s_{13}+\dot{m}_{12} s_{12}-\dot{m}_{19} s_{19}-\dot{m}_{2} s_{2}\right)$ \\
\hline Absorber & $\dot{Q}_{a}=\dot{m}_{16} h_{16}+\dot{m}_{22} h_{22}-\dot{m}_{17} h_{17}$ & $\dot{E} D_{a}=T_{0}\left(\dot{m}_{17} s_{17}-\dot{m}_{16} s_{16}-\dot{m}_{22} s_{22}-\dot{Q}_{a} / T_{a}\right)$ \\
\hline Condenser-2 & $\dot{Q}_{c 2}=\dot{m}_{13}\left(h_{13}-h_{14}\right)$ & $\dot{E} D_{c 2}=T_{0}\left(\dot{m}_{14} s_{14}-\dot{m}_{13} s_{13}-\dot{Q}_{c 2} / T_{c 2}\right)$ \\
\hline Evaporator-2 & $\dot{Q}_{e 2}=\dot{m}_{16}\left(h_{16}-h_{15}\right)$ & $\dot{E} D_{e 2}=T_{0}\left(\dot{m}_{16} s_{16}-\dot{m}_{15} s_{15}-\dot{Q}_{e 2} / T_{e 2}\right)$ \\
\hline Compressor & $\dot{W}_{\text {comp } 1}=\dot{m}_{24}\left(h_{24}-h_{23}\right)$ & $\dot{E} D_{\text {comp }}=T_{0} \dot{m}_{24}\left(s_{24}-s_{23}\right)$ \\
\hline Evaporator-3 & $\dot{Q}_{e 3}=\dot{m}_{23}\left(h_{23}-h_{26}\right)$ & $\dot{E} D_{e 3}=T_{0}\left(\dot{m}_{23} s_{23}-\dot{m}_{26} s_{26}-\dot{Q}_{e 3} / T_{e 3}\right)$ \\
\hline GC & $\dot{Q}_{g c}=\dot{m}_{24}\left(h_{24}-h_{25}\right)$ & $\dot{E} D_{g c}=T_{0}\left(\dot{m}_{25} s_{25}-\dot{m}_{24} s_{24}-\dot{Q}_{g c} / T_{g c}\right)$ \\
\hline SHE & $\dot{m}_{20} h_{20}-\dot{m}_{21} h_{21}=\dot{m}_{19} h_{19}-\dot{m}_{18} h_{18}$ & $\dot{E} D_{\text {she }}=T_{0}\left[\dot{m}_{19}\left(s_{19}-s_{18}\right)+\dot{m}_{21}\left(s_{21}-s_{20}\right)\right]$ \\
\hline TV-1 & $h_{9}=h_{10}$ & $\dot{E} D_{t v 1}=T_{0} \dot{m}_{10}\left(s_{10}-s_{9}\right)$ \\
\hline TV-2 & $h_{14}=h_{15}$ & $\dot{E} D_{t v 2}=T_{0} \dot{m}_{15}\left(s_{15}-s_{14}\right)$ \\
\hline TV-3 & $h_{21}=h_{22}$ & $\dot{E} D_{t v 3}=T_{0} \dot{m}_{22}\left(s_{22}-s_{21}\right)$ \\
\hline TV-4 & $h_{26}=h_{27}$ & $\dot{E} D_{t v 4}=T_{0} \dot{m}_{27}\left(s_{27}-s_{26}\right)$ \\
\hline Pump-1 & $\dot{W}_{p 1}=\dot{m}_{3}\left(h_{3}-h_{8}\right)$ & $\dot{E} D_{p 1}=T_{0} \dot{m}_{3}\left(s_{3}-s_{9}\right)$ \\
\hline Pump-2 & $\dot{W}_{p 2}=\dot{m}_{18}\left(h_{18}-h_{17}\right)$ & $\dot{E} D_{p 2}=T_{0} \dot{m}_{18}\left(s_{18}-s_{17}\right)$ \\
\hline
\end{tabular}

The End Losses are the function of the focal length of collector $(f)$, the length of the collector $(L)$ and the incident angle [18].

$$
\text { End Loss }=1-f \cdot \tan \theta / L
$$

The incident angle affects the direct normal irradiation on the mirror aperture. This effect is accounted for by the incident angle modifier $(K(\theta))$ which is given by [19].

$$
K(\theta)=\cos \theta-2.859621 \times 10^{-5} . \theta^{2}-5.25097 \times 10^{-4} . \theta(10)
$$

The total exergetic solar power absorbed by the receiver /absorber of PTC is given by

$$
\dot{E}_{r}=Q_{r}\left(1-T_{a} / T_{r}\right)
$$

The useful thermal power gain $\left(Q_{u}\right)$ by thermic fluid is given by

$$
\dot{Q}_{u}=m_{f} C_{p f}\left(T_{f, o}-T_{f, i}\right)
$$

The useful thermal power gain can also be expressed as:

$$
\dot{Q}_{u}=F_{r}\left[\dot{Q}_{r}-U_{l} A_{r}\left(T_{f, i}-T_{a}\right)\right]
$$

The useful exergetic gain $\left(E x_{u}\right)$ by thermic fluid is given by

$$
\dot{E}_{u}=\dot{m}_{f}\left[\left(h_{f, o}-h_{f, i}\right)-T_{0}\left(s_{f, o}-s_{f, i}\right)\right]
$$

In order to carry out thermodynamic analysis of such complex system, certain assumptions are required to simplify the analysis. The system operates under steady state condition, Pressure loss and pump work are neglected, the states of fluid at the exit of condenser and evaporator are saturated liquid and saturated vapor respectively, only physical exergy is considered and Lithium bromide solution in the absorber and generator are in equilibrium state at their respective pressure and temperature. The required operating parameters for the thermodynamic analysis are given in Table I. The relations obtained by the application of energy and exergy balance to each component of ARC, EORC and VCRC are outlined in Table II.

The performance of the system, based on first law of thermodynamics, can be evaluated using thermal efficiency $\left(\eta_{t h}\right)$ which is defined as the ratio of the desired cooling effect to the heat input. The thermal efficiency of solar triple effect system is expressed as:

$$
\eta_{t h}=\left(\dot{Q}_{e 1}+\dot{Q}_{e 2}+\dot{Q}_{e 3}\right) / \dot{Q}_{I}
$$

where $\dot{Q}_{I}$ is the total solar power input to the system and $\dot{Q}_{e 1}, \dot{Q}_{e 2}$ and $\dot{Q}_{e 3}$ are the refrigeration effect in ERC, ARC and VCRC respectively.

The exergy efficiency is expressed on the basis of second law of thermodynamics as

$$
\eta_{e x}=\left(\Delta \dot{E}_{e 1}+\Delta \dot{E}_{e 2}+\Delta \dot{E}_{e 3}\right) / \dot{E}_{I}
$$

where $\dot{E}_{I}$ is the total exergetic solar power input to the system and $\Delta \dot{E}_{e 1}, \Delta \dot{E}_{e 2}$, and $\Delta \dot{E}_{e 3}$ are the exergy change in evaporator-1 of ERC, evaporator-2 of ARC and evaporator-3 of VCRC respectively, which are expressed as: 


$$
\begin{aligned}
& \Delta \dot{E}_{e 1}=\dot{E}_{11}-\dot{E}_{10} \\
& \Delta \dot{E}_{e 2}=\dot{E}_{16}-\dot{E}_{15} \\
& \Delta \dot{E}_{e 3}=\dot{E}_{34}-\dot{E}_{33}
\end{aligned}
$$

\section{RESULTS AND DISCUSSION}

Based on the thermodynamic relations, a program is developed in Engineering Equation Solver (EES) [20]. The results thus obtained are presented and discussed in this section. For the base case calculations, oil temperature at PTC outlet is considered as $170^{\circ} \mathrm{C}$, turbine inlet pressure is 900 $\mathrm{kPa}$, turbine back pressure is $220 \mathrm{kPa}$ and gas cooler pressure is $9320 \mathrm{kPa}$. In order to carry out the parametric analysis, one parameter is varied while others remain constant.

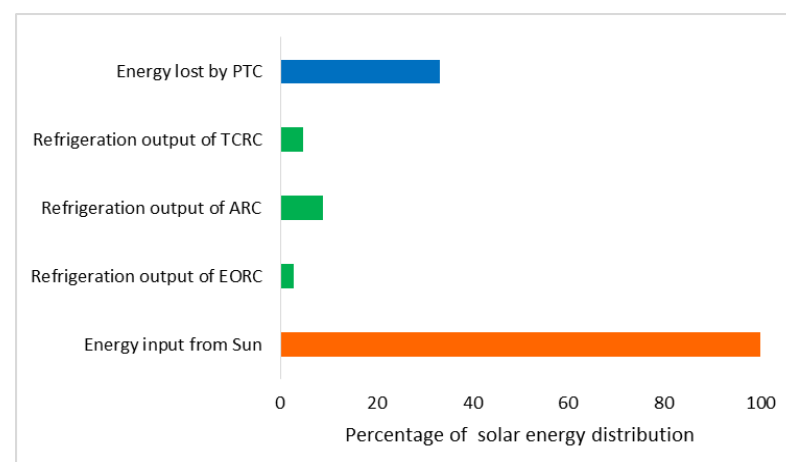

Fig. 2. Percentage of solar energy distribution for solar triple effect refrigeration cycle.

Fig. 2 shows the distribution of total solar energy falling on PTC for the base case. Out of the total energy input to the system, only $16.42 \%$ is obtained as desired refrigeration output, while rest of the solar energy is wasted. The refrigeration output of EORC, $\mathrm{ARC}$ and $\mathrm{VCRC}$ are respectively $2.85 \%, 8.82 \%$ and $4.75 \%$ of the total solar energy input. PTC is a major component of input energy loss as around $33 \%$ of input solar energy is wasted by it.

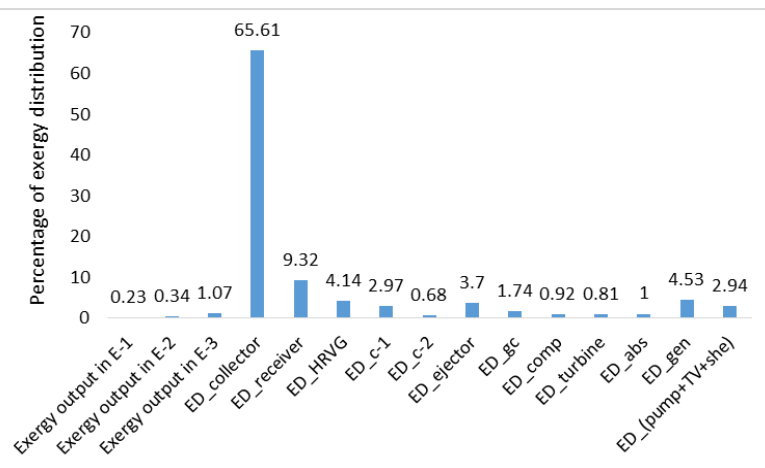

Fig. 3. Percentage of solar exergy distribution in output and destruction for solar triple effect refrigeration cycle.

Application of exergy analysis to the system provides valuable information on exergy distribution and destruction, as shown in Fig. 3. It is clear from the figure that out of the total solar exergy available to the system, only $1.64 \%$ is obtained as desired refrigeration output while remaining
98.36\% undergoes destruction and loss. The collection subsystem of PTC is the major source of thermodynamic inefficiency as it accounts for $65.61 \%$ destruction of solar exergy input to the system, followed by receiver of PTC, generator, HRVG, ejector and condenser-1. Thus, exergy analysis makes it clear that special attention needs to be given to these components while selecting their design and operating parameters, so as to enhance the performance of the complete system.

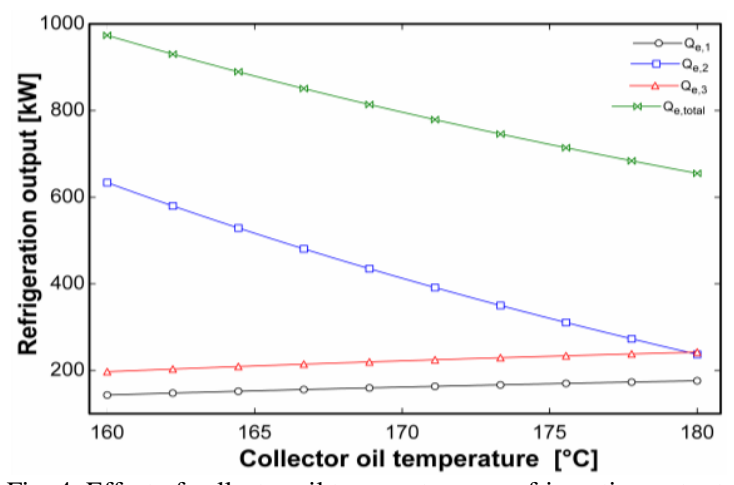

Fig. 4. Effect of collector oil temperature on refrigeration output.

Fig. 4 shows the variation of refrigeration output of EORC, ARC and VCRC with the increase in temperature of oil at PTC outlet (point 1). It is found in the analysis that refrigeration output of $\mathrm{ARC}$ decreases while that of EORC and VCRC increases with the increase in oil temperature. As oil temperature increases from $160^{\circ} \mathrm{C}$ to $180^{\circ} \mathrm{C}$, the refrigeration output of both EORC and VCRC increases by almost $23 \%$. Increased temperature results in better quality of refrigerant vapour at turbine inlet, thus more power is available from turbine to VCRC. This causes increased mass flow rate of refrigerant through evaporator-3, resulting in increased refrigerating effect in VCRC. Also, improved quality of vapour refrigerant at turbine inlet results in better quality of refrigerant at the exit of turbine. This causes increase in velocity of primary motive fluid at nozzle exit, which creates greater vacuum at secondary vapour entrance to ejector. This causes more secondary refrigerant to flow through evaporato- 3 and hence higher refrigerating effect in EORC. The cooling capacity of ARC reduces by $62.62 \%$ with the increase in oil temperature within the given range. The fall in cooling capacity of ARC is because of the decrease in oil temperature at the exit of HRVG (point 2). Thus input heat to ARC decreases which causes lesser refrigerant (water) generation in the generator. The magnitude of refrigeration output of ARC is much more than that of EORC and VCRC, therefore, the total refrigeration output follows the trend of variation of refrigeration output of ARC. The total cooling capacity of the system registers a decline of $32.72 \%$ with the increase in oil temperature from $160^{\circ} \mathrm{C}$ to $180^{\circ} \mathrm{C}$.

Fig. 5 represents the variation of first law based thermal efficiency and second law based exergy efficiency with oil temperature. Appreciable drop in thermal efficiency of the system is observed with the rise in temperature of oil, whereas exergy efficiency remains almost constant with the change in temperature. The decrease in thermal efficiency is around $32 \%$, and it is so because of drastic fall in overall cooling capacity with the increase in oil temperature. 


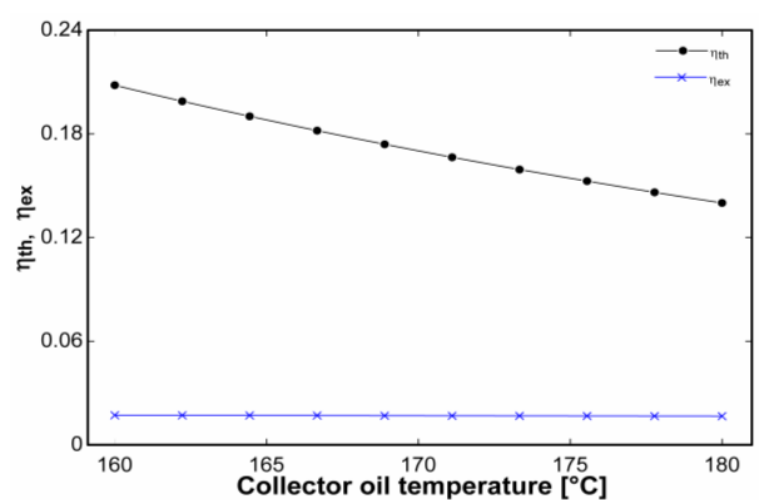

Fig. 5. Variation of efficiency with collector oil temperature.

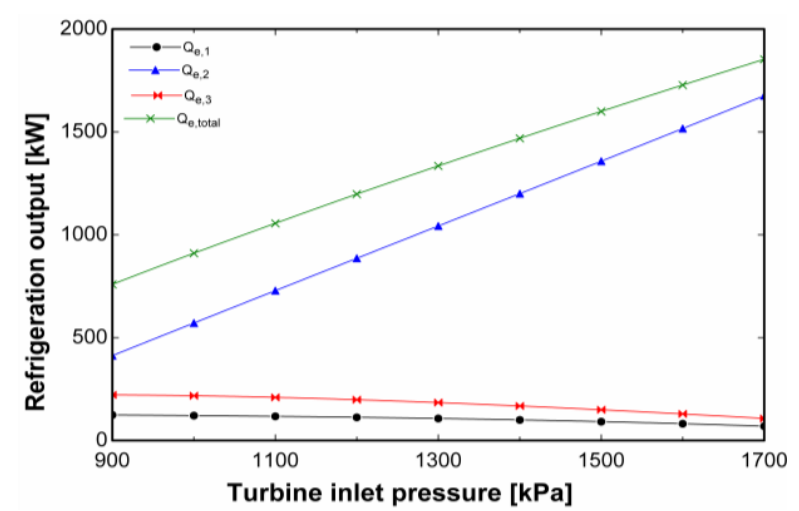

Fig. 6. Variation of refrigeration output with turbine inlet pressure.

Fig. 6 shows the effect of turbine inlet pressure on cooling capacities of EORC, ARC and VCRC and on total cooling capacity. Increase in turbine inlet pressure from $900 \mathrm{kPa}$ to $1700 \mathrm{kPa}$ causes reduction in cooling capacities of EORC and VCRC by $43.79 \%$ and $51.67 \%$ respectively. Contrary to this, the cooling capacity of ARC increases with increase in turbine inlet pressure. It is more than three times at $1700 \mathrm{kPa}$ than at $900 \mathrm{kPa}$. Consequently, total cooling capacity registers an increase of $144 \%$. Thus it can be said that turbine inlet pressure has profound effect on cooling capacity. The rise of turbine inlet pressure reduces the mass flow rate of refrigerant (R141b) vapours generated in HRVG. Thus, heat input to EORC decreases whereas heat input to ARC increases. Lower mass flow rate and lower heat input in EORC results in lower refrigeration and power output. Lower power generation in EORC causes lower power input to VCRC and thus lower refrigeration output of VCRC. Increase in availability of heat to ARC results in increase in cooling capacity of ARC.

Fig. 7 shows the variation of energy and exergy efficiency of solar driven triple effect refrigeration system with increase in turbine inlet pressure. The thermal efficiency increases significantly as compared to exergetic efficiency. The increase in thermal and exergetic efficiency, with the increase in turbine inlet pressure, is $144 \%$ and $24 \%$ respectively.

The effect of gas cooler pressure on refrigeration output is shown in Fig. 8. The gas cooler pressure is varied between $8000 \mathrm{kPa}$ and $11000 \mathrm{kPa}$. The increase in gas cooler pressure affects only the output of VCRC, the outputs of ARC and EORC remains unaffected. With the increase in gas cooler pressure, refrigeration output of VCRC first increases and then starts decreasing. Therefore, there is a particular value of gas cooler pressure corresponding to which cooling capacity of VCRC and hence total cooling capacity is maximum. The gas cooler pressure corresponding to maximum cooling capacity for the base case is $9333 \mathrm{kPa}$.

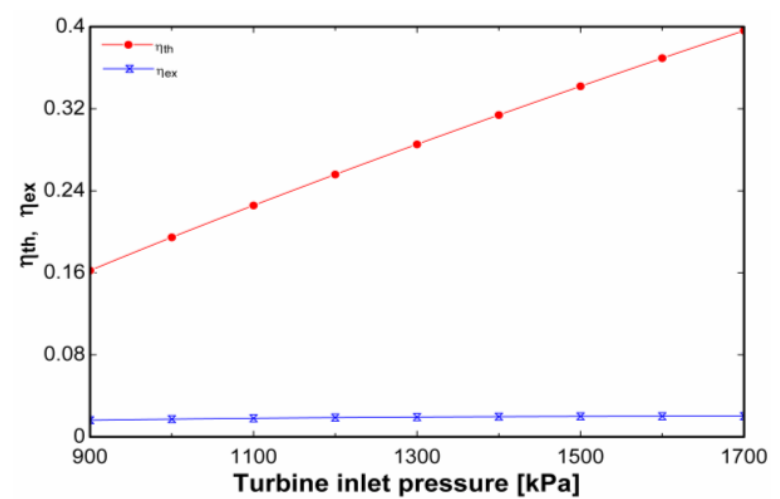

Fig. 7. Variation of efficiency with turbine inlet pressure.

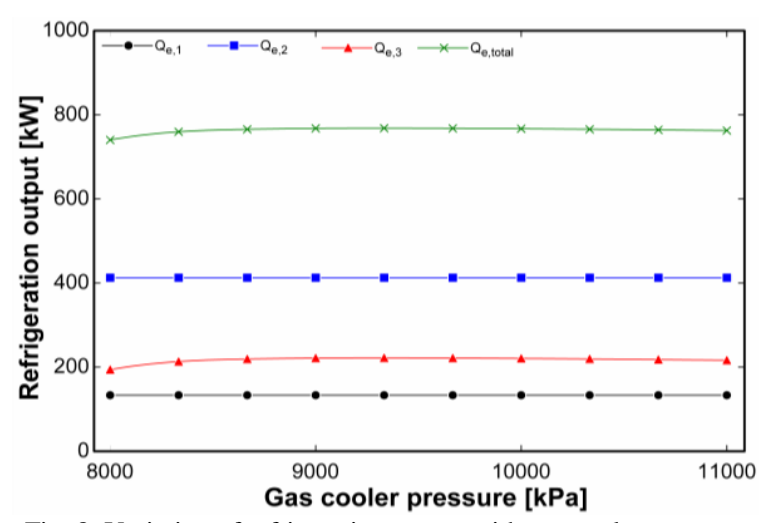

Fig. 8. Variation of refrigeration output with gas cooler pressure.

Fig. 9 shows the variation of thermal efficiency and exergy efficiency with increase in gas cooler pressure. Like cooling capacity, both thermal and exergetic efficiencies attains a maximum value at a particular gas cooler pressure. The gas cooler pressure corresponding to maximum thermal efficiency and maximum exergetic efficiency is same. The maximum values of thermal and exergetic efficiencies, for the base case, are $16.43 \%$ and $1.64 \%$ respectively and the corresponding gas cooler pressure is $9333 \mathrm{kPa}$. Thus, it can be concluded that maximum refrigeration output, maximum thermal efficiency and maximum exergetic efficiency are obtained at same gas cooler pressure, other conditions being constant.

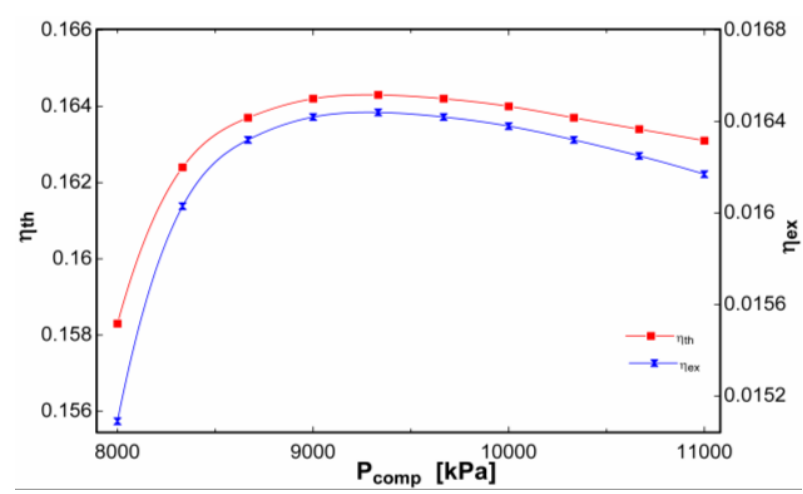

Fig. 9. Variation of efficiency with gas cooler pressure.

\section{CONCLUSION}

Based on the energy and exergy analysis of solar triple 
effect refrigeration cycle, following conclusions can be made.

1) Irreversibility is maximum due to PTC, generator, HRVG and ejector. Therefore, design of these components requires extra attention for better performance of the system.

2) Exergy output of solar triple effect cycle is much less than energy output. About $16.82 \%$ is obtained as desired energy output while only $1.64 \%$ is obtained as desired exergy output.

3) The exergy output of VCRC is much more than the exergy output of ARC and EORC for a given solar energy source. It is $1.07 \%$ for VCRC while for ARC it is $0.34 \%$ and for EORC it is merely $0.23 \%$.

4) Maximum energy and exergy efficiency occurs at a particular gas cooler pressure for given set of conditions.

\section{ACKNOWLEDGMENT}

The support of Ministry of New and Renewable Energy (MNRE), Government of India, is duly acknowledged.

\section{REFERENCES}

[1] L. O. S. Buzelin, S. C. Amico, J. V. C. Vargas, and J. A. R. Parise, "Experimental development of an intelligent refrigeration system," International Journal of Refrigeration, vol. 28, pp. 165-175, 2005.

[2] B. Choudhury, P. K. Chatterjee, and J. P. Sarkar, "Review paper on solar-powered air conditioning through adsorption route," Renewable and Sustainable Energy Reviews, vol. 14, pp. 2189-2195, 2010.

[3] B. F. Tchanche, G. Lambrinos, A. Frangoudakis, and G. Papadakis, "Low-grade heat conversion into power using organic Rankine cyclea review of various applications," Renewable and Sustainable Energy Reviews, vol. 15, no. 8, pp. 3963-3979, 2011.

[4] D. Sun, I. W. Eames, and S. Aphornratana, "Evaluation of a novel combined ejector refrigeration cycle-I: computer simulation," International Journal of Refrigeration, vol. 19, pp. 172-180, 1996.

[5] D. Hong, G. Chen, L. Tong, and Y. He, "A novel ejector-absorption combined refrigeration cycle," International Journal of Refrigeration, vol. 34, pp. 1596-1603, 2011.

[6] J. Wang, Y. Dai, and Z. Sun, "A theoretical study on a novel combined power and ejector refrigeration cycle," International Journal of Refrigeration, vol. 32, pp. 1186-1194, 2009.

[7] Y. Dai, J. Wang, and L. Gao, "Exergy analysis, parametric analysis and optimization for a novel combined power and ejector refrigeration cycle," Applied Thermal Engineering, vol. 29, pp. 1983-1990, 2009.

[8] D.Y. Goswami and F. Xu, "Analysis of a new thermodynamic cycle for combined power and cooling using low and mid temperature solar collectors," Journal of Solar Energy Engineering, vol. 121, no. 2, pp. 91-97, 1999.

[9] A. A. Hasan, D. Y. Goswami, and S. Vijayaraghavan, "First and second law analysis of new power and refrigeration thermodynamic cycle using solar heat source," Solar Energy, vol. 73, no. 5, pp. 385-393, 2002.

[10] C. Martin and D. Y. Goswami, "Effectiveness of cooling production with a combined power and cooling thermodynamic cycle," Applied Thermal Engineering, vol. 26, pp. 576-582, 2006.

[11] N. Zhang and N. Lior, "Methodology for thermal design of novel combined refrigeration/power binary fluid systems," International Journal of Refrigeration, vol. 30, no. 6, pp. 1072-1085, 2007.

[12] B. K. Agrawal and M. N. Karimi, "Thermodynamic performance assessment of a novel waste heat based triple effect refrigeration cycle," International Journal of Refrigeration, vol. 35, pp. 1647-1656, 2012 .
[13] A. Khaliq, R. Kumar, I. Dincer, and F. Khalid, "Energy and exergy analyses of a new triple-staged refrigeration cycle using solar heat source," Journal of Solar Energy Engineering, vol. 136, no. 1, 2013.

[14] A. Khaliq, "Performance analysis of a waste-heat-powered thermodynamic cycle for multi-effect refrigeration: Waste-heat-driven multi-effect cooling cycle," International Journal of Energy Research, vol. 39, pp. 529-542, 2015.

[15] K. E. Herold, R. Radermacher, and S. A. Klein, Absorption Chillers and Heat Pumps, USA: CRC Press, 1996.

[16] V. S. Reddy, S. C. Kaushik, and S. K. Tyagi, "Exergetic analysis and performance evaluation of parabolic trough concentrating solar thermal power plant (PTCSTPP)," Energy, vol. 39, no. 1, pp. 258-273, 2012.

[17] R. Petela, "Exergy of heat radiation," Journal of Heat Transfer, vol. 86, pp. 187-192, 1964.

[18] F. Lippke, "Simulation of the part-load behaviour of a 30 MWe SEGS plant,” Report No. SAND95-1293, SNL, Alburquerque, NM, USA, 1995.

[19] M. J. Montes, A. Abanades, J. M. Martinez-Val, and M. Valdes, "Solar multiple optimization for a solar only thermal power plant using oil as heat transfer fluid in the parabolic trough collectors," Solar Energy, vol. 83, pp. 2165-2176, 2009.

[20] S. A. Klein and F. Alvarado, Engineering Equation Solver (EES), WI: F-Chart Software, 2005.

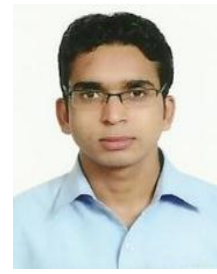

Manoj Dixit is a Ph.D. research scholar in the Centre for Energy Studies at Indian Institute of Technology (IIT), Delhi, India. He completed his M.Tech. degree in thermal engineering from Delhi Technological University (erstwhile Delhi College of Engineering), Delhi in 2012. His research areas of interest are solar cooling, thermal system design, analysis, and optimization and energy conservation, and heat recovery.

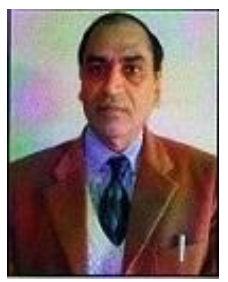

S. C. Kaushik is a professor in the Centre for Energy Studies at Indian Institute of Technology (IIT), Delhi. He received his Ph.D. in plasma science from IIT Delhi after his distinguished first position in master's degree in science (electronics) from Meerut University. His research fields of activities include thermal science and engineering, energy conservation and heat recovery, solar refrigeration and airconditioning, solar architecture, and thermal storage and power generation. He has made significant contributions in these fields as evident by his above 300 research publications in journals of repute at national and international levels. He is a pioneer researcher on exergy analysis and finite time thermodynamics of energy systems at national \& international level and a leading expert on alternative refrigeration and air conditioning technologies. He has co-authored/ edited several books on energy related topics in his academic carrier.

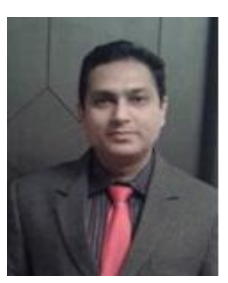

Akhilesh Arora is working as an assistant professor in the Department of Mechanical Engineering at Delhi Technological University (erstwhile Delhi College of Engineering) Delhi since 2004. Prior to joining Delhi College of Engineering, he has also worked at the College of Military Engineering, Pune in the capacity of lecturer for two years. He obtained his Ph.D. and master degrees from the Indian Institute of Technology, Delhi, in 2010 and 1997 respectively. His research area is refrigeration and air-conditioning, thermal science and engineering, energy conservation and heat recovery. He has published number of research papers in international and national journals. 

Wind Energy 
